\title{
Proceedings of the National Mathematics Initiative Workshop on Nonlinear Integrable Systems and their Applications
}

Bharathidasan University,

Tiruchirappalli 620 024,

India

February 24-March 1, 2014

Editors

M LAKSHMANAN

P MURUGANANDAM

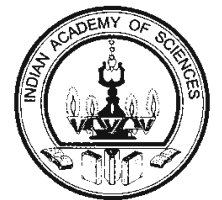

Published by

Indian Academy of Sciences

Bengaluru 